\title{
INEQUALITIES FOR VOLUMES AND MEDIANS OF TWO SIMPLICES
}

\author{
YANG SHIGUO
}

\begin{abstract}
In this paper, some inequalities for volumes and medians of two $n$-dimensional sim-
\end{abstract} plices are established.

\section{Mathematics subject classification (2000): 51M16, 51M25.}

Key words and phrases: Simplex, volume, median, inequality.

\section{REFERENCES}

[1] D. Pedoe, Thinking geometrically, Amer. Math. Monthly 77 (1970), 711-721.

[2] P. CHIA - KuEI, Sharpening the Neuberg - Pedoe inequality I, Crux. Math. 10 (1984), 68-69.

[3] YANG Lu, ZHANG JingZHONG, A generalization to several dimension of the Neuberg - Pedoe inequality with applications, Bull. Austral. Math. Soc. 27 (1983), 203-214.

[4] LENG GAngson, Inequalities for edge lengths and volumes of two simplices, Geom. Dedicata. 68 (1997), 43-48.

[5] Zhang Hanfang, An extension of the high - dimensional Pedoe inequality, J. Xuzhou Teachers College 14 (1996), 4-7.

[6] YANG SHIGUO, Three geometric inequalities for a simplex, Geom. Dedicata 57 (1995), 105-110. 